DOI: 10.20472/IAC.2019.048.038

\author{
ABAY MULATU \\ Coventry University, United Kingdom
}

\title{
ON MEASURES OF THE STRINGENCY OF ENVIRONMENTAL POLICY
}

\begin{abstract}
:
Adequately measuring the stringency of national environmental regulation is a crucial issue in the empirical literature on the link between environmental policy and economic performance such as productivity, export competitiveness and foreign investment flows. As Levinson (2008, p. 1) argues, "The problem is not merely one of collecting the appropriate data; merely conceiving of data that would represent it is difficult". The empirical literature on the link between environmental regulation and economic outcomes contains various proxies of stringency of environmental regulation. The divergent nature of these proxies is arguably a major factor for the mixed evidence witnessed in this literature (Millimet and Roy 2016; Mulatu 2017, 2018 ). The construction or use of the various measures of stringency is seldom preceded by a discussion of what exactly stringency is. In this paper, we develop a simple analytical model - based on the Environmental Kuznets Curve - that captures the idea of relative stringency as a differential preference with respect to the environment. The model serves as a general framework to estimate a measure of national environmental standards for a selected group of countries.
\end{abstract}

\section{Keywords:}

Environmental-Regulation, Environmental Kuznets Curve, Co2 emissions 